\title{
O desenho como membrana: processos, aprendizados e compartilhamentos
}

\author{
Márcio Diegues (UERJ)
}

\begin{abstract}
RESUMO
O presente artigo pretende refletir sobre a importância do desenho como ferramenta sensível e produtora de conhecimento, assim como, uma técnica porosa, que atravessa e faz parte de diversos modos do saber. Em sua capacidade plástica de criar imagens, o desenho também carrega a possibilidade de emancipar a imaginação, fazendo parte de nossos projetos de vida, assim como, também, de um projeto cultural, político e social em perspectiva mais ampla. Com essas premissas, traço reflexões sobre a prática e a operação dessa linguagem, ampliando os processos porosos do desenho às urgências e necessidades do cotidiano vivido e compartilhado.
\end{abstract}

PALAVRAS-CHAVE: Desenho; membrana; arte contemporânea; aprendizagem.

\section{RESUMEN}

El presente artículo pretende reflexionar sobre la importancia del deseño como instrumento sensible y productor de conocimiento, así como, una técnica porosa, que cruza y forma parte de diversas formas de conocimiento. En su capacidad plástica para crear imágenes, el deseño también lleva la posibilidad de emancipar la imaginación, como parte de nuestros proyectos de vida, así como un proyecto cultural, político y social en una perspectiva más amplia. Con estas premisas, hago reflexiones sobre la práctica y el funcionamiento de este lenguaje, extendiendo los procesos porosos de deseño a las urgencias y necesidades de la vida cotidiana vivida y compartida.

PALABRAS CLAVE: Deseñi, membrana; arte contemporáne; aprendizaje.

\section{INTRODUÇÃO}

Este artigo se apresenta estruturado entre minha prática de artista, professor e pesquisador, aliando em suas partes, fragmentos de textos produzidos na dissertação de mestrado, em 2017, onde a ideia do "desenho como membrana" foi primeiramente abordada. No presente texto, busco desdobrar a qualidade porosa que o conceito membranoso do desenho carrega em si, alinhavando questões processuais e de aprendizado, que ampliam nossa visão sobre as possibilidades de atuação desta linguagem no 


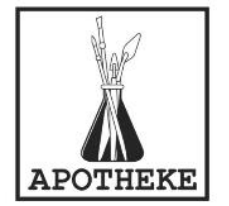

\section{REVISTA APOTHEKE}

ISSN 2447-1267

v.5, n.2, ano 5, 2019

imaginário, assim como, seu uso como uma ferramenta de construção e transformação político-social.

\section{O QUE É O DESENHO?}

"O que é desenhar? Como o conseguimos? É a ação de abrirse através de um muro de ferro invisível, que parece encontrar-se entre o que sentimos e o que podemos". Van Gogh.

Iniciar o texto com esta pergunta é crucial para pensarmos em uma ou mais definições para esta linguagem silenciosa, no entanto, depois de falarmos e pensarmos tudo o que seria possível dizer sobre o desenho, vemos essa busca por definições ruir, e, ao mesmo tempo, se ampliar além do que foi dito e traçado.

Mas o que seria o desenho? Uma ação-pensamento, na qual o traço e a linha fundem em uma mesma superfície o tempo do mundo e o tempo do ser? No relato da artista, Geórgia Kyriakakis, percebemos que o desenho the ensinou a importância de arriscarse, e assim ela nos diz:

\footnotetext{
A primeira lição que o desenho me ensinou foi a necessidade de uma atitude contundente perante o fazer - saber correr os ricos que cada trabalho apresenta. Quando hoje opero a partir dos limites entre o equilíbrio e a instabilidade quando tenciono o limite de permanência e fragilidade das coisas -, é como se estivesse constantemente transpondo para o mundo físico e concreto o perigo que um gesto gráfico carrega e a precisão que ele requer. (KYRIAKAKIS, apud DERDYK, 2007, p. 161).
}

Estrutura-estruturante de incontingências: com formas cheias, vazios, massas, tramas, manchas, pontos, sulcos, retas, paralelas, encruzilhadas e curvas; o desenho é uma rede de signos gráficos que indiciam algo. Algo que está além das linhas, que está no ar, no éter, na organização dos organismos e dos mecanismos, naquilo que olhamos e vemos sob potência de imagem - imagem porosa, intrincada e fluida, que em sua capacidade de transmissão de sentidos, partilha significados na pele visual da língua-desenho.

Enfaticamente o desenho e sua capacidade de evocar, de representar, de colocar-nos dentro do jogo do visível, o expande de linguagem gráfica a um campo imaterial de conhecimento e vida, onde ele próprio, mesmo antes de acontecer no papel, acontece em 


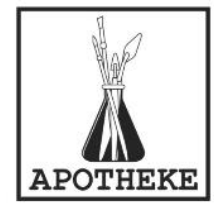

\section{REVISTA APOTHEKE}

ISSN 2447-1267

v.5, n.2, ano 5, 2019

intuição, em pulsão ${ }^{2}$ sensível - acontece, sobretudo, no ato de ver e está ligado ao nosso imaginário produtor de imagens membranosas, ao nosso âmago imaginário que cria e recria as impressões do mundo em dada posição de ancoragem do corpo no campo visual, organizando nossas percepções em sistemas vivos e significantes. Traçáveis ou não. Ainda como um trabalho interno e externo, de reconhecimento sensível e de internalizações do mundo visível, o desenho desperta em nós muitas camadas membranosas de imagens: lembranças, fluxos e jorros de formas, percepções viscerais, padrões visuais que se embaralham e se ligam em embaraçadas teias de sentidos e significados, disponíveis ao pensamento para serem materializados pelos gestos.

A fenomenologia do desenho reside na linha e em sua ideia de delinear um não-limite; a linha como borda dos corpos que se abismam e transbordam, a linha como horizonte incontido, a linha como índice umbilical de nossa relação oscilatória com o mundo visível: traço e rastro percebido como desenho e como uma profunda verdade do ver e do não-ver. Orbital oscilatório de uma grafologia do olhar e do olhante.

Se o olhar se amplia pelo desenho, e, se o desenho nos possibilita criar camadas de sentido para o visível, então os limites da visualidade nunca foram tão oscilantes e elásticos como na contemporaneidade. As ações através do desenho se ampliaram às instalações, performances, coletas e procedimentos

\footnotetext{
2 Pulsão: Segundo Sigmund Freud (Áustria, 1856 - 1932), "a 'pulsão' nos aparece como um conceito-limite entre o psíquico e o somático, como representante psíquico dos estímulos oriundos do interior do corpo que alcançam a psique, como uma medida da exigência de trabalho que é imposta ao psíquico em decorrência de sua conexão com o corpóreo." E mais a frente, ele também diz: "Naturalmente, nada impede admitir que as próprias pulsões, pelo menos em parte, sejam sedimentos de efeitos de estímulos externos, que, no decurso da filogênese, influenciaram modificações na substância viva." FREUD, Sigmund. Trecho retirado do texto: As pulsões e os destinos de pulsões. Tradução de Verlaine Freitas, a partir de: FREUD, Sigmund. Triebe und Triebschicksale. In:_ Gesammelte Werke, vol.X. Frankfurt am Main: Fischer, pp.209-232. Fonte: http://www.verlaine.pro.br/txt/freudpulsoes.pdf
} 


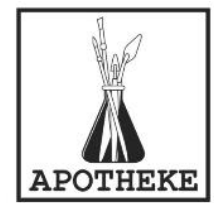

dos mais variados adotados pelos artistas que constroem, independente de seus meios, as conexões entre nossa imaginação e o mundo. Pelo desenho ativamos a imagem como um campo de ação bidimensional no real.

A produção de arte, desde os anos 60, parece ter noção consciente desse campo poroso e interdisciplinar, não só com o desenho, mas com todas as linguagens e práticas artísticas que tomaram forma e importância a partir de atitudes, ações, construções, processos complexos, novos materiais e questões diversas ligadas às demandas humanas. Esse ponto de vista especulativo sobre o mundo é perceptível na prática e na criação artística atual, onde as ações dos artistas na contemporaneidade continuam transmutando o potencial visual da vida e da arte, expandindo seus efeitos à realidade, intervindo em espaços públicos e privados, buscando parcerias, olhando e retomando velhos objetos de desejo coletivo, ressignificando as práticas das tradições artísticas já esquecidas, mergulhando na experiência do olhar e em sua capacidade de ver e de criar imagens para serem vistas e absorvidas.

Em certa medida, o desenho vira um hábito e é habitado pelo ser que o pratica, ativado como um sexto sentido, como algo vívido, impregnado e impregnante, que desperta realmente nosso modo de ver e nos relacionarmos com o visível. Uma sensibilidade que, se cultivada, cresce junto com o mundo e com nossa visão (metodologia íntima), e ajuda-nos a experimentar cada sutileza da realidade interna e externa em seu poder poroso de transpor, de permear, de permitir um fluxo de trocas (relação coletiva), dissoluções, aglutinações, autofagias, gerações espontâneas de imagem, de visualidade e imaginação. O desenho produz membranas do ver para o ver. E nos instala essas membranas no jogo entreolhares e entre-corpos, entre-imagens e entre-imaginações.

Desenhar pode ser um verbo que nos faz experimentar o limiar das existências e nos transforma junto com o que é vivido e grafado, traçado e riscado continuamente. Se o experimento 


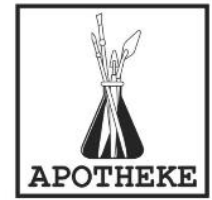

passa a mediar às relações entre sujeito e objeto nas ciências empíricas, o desenho, enquanto linguagem e ação, passa a mediar nossas relações porosas com o mundo observado e as relações que o objeto desenhado - e sua membrana imagética - passam a mediar com o observador. Há uma rede de conexões no desenho: "Ele é um instrumento da imaginação, tentando capturar alguma realidade/estrutura oculta, ainda desconhecida", como nos fala Laerte Sodré (1973-), físico e astrônomo da USP, em seu texto, "Desenho na Astronomia". (SODRÉ, apud DERDYK, 2013, p. 239).

Desse modo, pensar o desenho como uma membrana, é afirmar que através de sua prática, uma torrente/rede de percepções, dados sensíveis, vivências e ações passam a operar a imaginação como suporte, e a linguagem, como travessia. Segundo Robert Smithson, artista norte-americano precursor da Land Art, nos anos de 1960-70, "Temos que fabricar nossas regras à medida que avançamos pelas avalanches de linguagem e sobre os terraços da crítica" (SMITHSON, apud FERREIRA, 2006. p. 192). Em seu texto, Smithson, pontua a necessidade do artista criar seus próprios meios de avançar pelos desafios práticos e teóricos que as linguagens nos abrem, sobre os terraços da crítica, aos quais, nos encontramos desde sempre, pois, o trabalho plásticoconceitual é também uma membrana imagética coletiva a ser continuamente trabalhada e revisitada.

Mas o que é uma membrana? A membrana é uma estrutura permeável que envolve todas as células. Seu papel é o de possibilitar a entrada e saída de substâncias do corpo celular, protegendo-o, nutrindo-o, excretando, e, também, delimitando-o porosamente. De certo modo, a membrana é um invólucro, uma pele, um tecido ou uma trama, por vezes sutil e estruturante de relações entre o interior e o exterior daquilo que envolve, portanto, a membrana é uma estrutura fluída.

Então, quais as motivações e implicações de se propor o desenho como membrana? As motivações partem de um desejo em falar do desenho no agora, em pensar o desenho na urgência das questões 


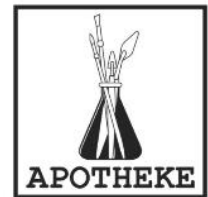

\section{REVISTA APOTHEKE}

ISSN 2447-1267

v.5, n.2, ano 5, 2019

cotidianas e em como o desenho pode se transformar em uma possibilidade de ação e emancipação subjetiva, política e crítica. Em um segundo plano, a motivação também parte de um desejo em pontuar o desenho como possibilidade de compartilhamento, proliferação e contágio do imaginário com novas possibilidades de existir, resistir e reagir coletivamente, pensando justamente a porosidade membranosa dessa linguagem como capacidade dispersora de ideias e de atuação política nos imaginários.

Já as implicações dessa justaposição biológica e semântica, do desenho com a membrana, precisamos refletir a partir das próprias operações do desenho nas várias etapas do processo de criação artística e de aprendizado, de compartilhamento e discussão, ressaltando a interação corporal e mental que o desenho desperta no desenhador do desenho, assim como, no observador da imagem desenhada. Como fala o filósofo francês Maurice Merleau-Ponty, em seu ensaio, "O olho e o espírito": A linguagem significa quando, em vez de copiar o pensamento, deixase desfazer e refazer por ele. Traz seu sentido como o rastro de um passo significa o movimento e o esforço de um corpo" (MERLEAUPONTY, 2013, p. 67).

Desse modo, podemos pensar que trazer o sentido à tona, do interno para o externo, do núcleo até a superfície da membrana, eis uma função indispensável ao papel social e de compartilhamento do desenho: esse pôr à mostra, esse escancaramento do pensamento para outro imaginário. Cabe-nos agora, perguntar e investigar, de que maneiras essas passagens e travessias se dão e no que elas implicam.

\section{O PAPEL SOCIAL DO DESENHO: o desenho como potência de transformação imaginária.}

"Em permanente mutação, a natureza do desenho é sempre a mesma e sempre outra!". Edith Derdyk. 
Se podemos experimentar o desenho como uma membrana, logo, isso implica, repensar a sua dimensão compartilhável e a capacidade que ele tem de transmitir sentidos, de criar laços com o presente à nível individual e coletivo. Desse modo, a ideia e a pulsão de desenhar se ligam a um projeto de coexistência e resistência, gerando um novo ponto de vista sobre o mundo, e, lançando nesse mesmo mundo, um ancoradouro para outros olhares visualizarem desse lugar outras vistas possíveis.

o que quero dizer é que o desenho é também uma ferramenta política de partilha e reação ao mundo. Por essa capacidade de criar pontos de resistência na visão e na imaginação, ele também assume 0 papel de testemunhar e de fazer sobreviver as imaginárias periféricas que, se não estão mapeadas nas narrativas dominantes, ocupam sempre as margens das histórias oficiais ou nem aparecem nas grandes narrativas da história da arte.

É possível compreendermos a vastidão de gestos que o desenho alcança hoje, só de olharmos para as paredes e muros das cidades, todos cobertos de símbolos, signos e imagens grafitadas, pichadas, feitas com tinta e pincel, ou mesmo, criadas com um prego arrastado contra o cimento; as superfícies das peles tatuadas, recobertas de desenhos, de manchas, de rabiscos não legíveis ou mesmo línguas e caligrafias de outras culturas. Com a internet, é possível pensarmos em uma biblioteca quase infinita de desenhos à nossa disposição, sites de procura empilham imagens por temas pesquisados, sobrepondo randomicamente imagens do mundo antigo, moderno e contemporâneo, com tipologias, iconografias, clichês de todos os tipos e épocas. Pilhas e mais pilhas de imagens virtualizadas e transmitidas a uma pluralidade de monitores, telas de celulares, televisões e dispositivos móveis.

A rápida circulação de informação na internet acentuou ainda mais a capacidade membranosa do desenho em se espalhar, em ramificar, em ser copiado, adaptado, em ser escalonado, 
reapropriado, ressignificado. O ser humano vive rodeado de imagens e as imagens fazem parte, mais do que nunca, do seu processo de aprendizado e de transmissão de cultura. Por este sentido comunitário, coletivo e de partilha do sensível³, o desenho atuar em sua potência comunicativa e política, e aponta para uma urgência de transformação social e imaginária.

A dimensão social do desenho é a dimensão política de todo gesto, de toda fala e ação. Assim, o desenho que acontece no plano bidimensional se insere no real, pois ataca nossa visão com questões e necessidades profundas do agora. Essa partilha sensível que o desenho opera está na capacidade mesma que a arte tem de se inserir em outros campos do saber e da vida. Se a política possui uma dimensão estética, como nos fala Jacques Rancière, será que o desenho não poderia operar seus efeitos de partilha e transformação no campo da consciência política e da existência cotidiana, e, também, na própria realidade vivenciada? Se sim, eis aqui a reafirmação do papel social do artista como um tipo de agente transformador da realidade cultural.

Citando, Jacques Rancière: "A política ocupa-se do que se vê e do que se pode dizer sobre o que é visto, de quem tem competência para ver e qualidade para dizer, das propriedades do espaço e dos possíveis do tempo" (RANCIÉRE, 2005, P.17). Essa dinâmica de partilha, que também acontece como uma forma de ensino e de aprendizagem estética, está na raiz de toda sociedade ou coletivo, como uma maneira de realizar a manutenção da cultura e da economia imaginária de toda comunidade.

\footnotetext{
3 "Denomino partilha do sensível o sistema de evidências sensíveis que revela, ao mesmo tempo, a existência de um comum e dos recortes que nele definem lugares e partes respectivas. Uma partilha do sensível fixa, portanto, ao mesmo tempo, um comum partilhado e partes exclusivas. Essa repartição das partes e dos lugares se funda numa partilha de espaços, tempos e tipos de atividade que determina propriamente como o comum se presta a participação e como uns e outros tomam parte nesta partilha" RANCIÈRE, Jacques. P. 15. In: A partilha do sensível. São Paulo: Editora 34, 2005.
} 


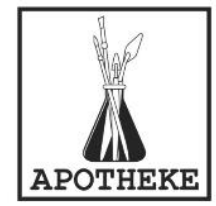

\section{REVISTA APOTHEKE}

ISSN 2447-1267

v.5, n.2, ano 5, 2019

Esse pensamento que integra pela sensibilização, foi uma das preocupações centrais do poeta anarquista, literato e crítico de arte inglês, Herbert Read, ao escrever "A educação pela arte", publicado pela primeira vez em 1943. Com o intuito de criar um currículo comum para a educação, Read propõe que todo currículo escolar seja baseado na arte e no princípio das experiências estéticas como motriz para a ação pedagógica e para as construções do saber científico se unirem em um processo educativo integrador. Ainda em seu livro, Read também salienta - quão benéfico pode ser o processo educativo ao reconciliar a singularidade individual à unidade social, e ele diz:

o objetivo da educação, portanto, só pode ser o de desenvolver, juntamente com a singularidade, a consciência social ou reciprocidade do indivíduo. Como resultado das infinitas permutações da hereditariedade, o indivíduo será inevitavelmente único, e essa singularidade, por ser algo que ninguém mais possui, será de valor para a comunidade. (READ, 2013, p.06).

No exercício do ensino, seja de arte ou de outros saberes, - desenho também opera sua capacidade membranosa e integradora, aliando em sua potência gráfica, as capacidades simbólicas e cognitivas essenciais para a reflexão e compreensão de conteúdos importantes para o desenvolvimento intelectual e psicomotor coletivo. Tanto o desenho, como as artes no geral, são, no pensamento de Read, a base comum às ciências e ao desenvolvimento cognoscívo de todo indivíduo, pois o princípio da educação pela arte, vem de uma pedagogia baseada na percepção e na experiência estética enquanto processos compartilhados e construtores do saber. Desse modo, Read nos diz: "Portanto, o objetivo da educação é a formação de artistas - pessoas eficientes nos vários modos de expressão". (READ, 2013, p.12).

Se a afirmação de Read nos parece muito incisiva, devemos ampliar nossas concepções sobre o termo artista: não mais restrito à ser um praticante de técnicas artesanais, criador de artifícios e imagens funcionais, mas agora, sobretudo na 


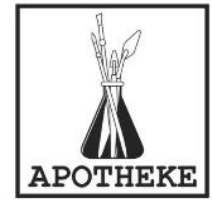

contemporaneidade, o artista é um propositor de experiências estéticas, questionadoras da própria realidade histórica, social, ambiental, e por este sentido, a obra de arte torna-se também uma forma especulativa, imaginária e política - um projeto emancipador de imaginários que encontra-se à deriva de todo tipo de experiência com o mundo. Para Rancière: "É esse modo específico de habitação do mundo sensível que deve ser desenvolvido pela 'educação estética' para formar homens capazes de viver numa comunidade política livre" (RANCIÈRE, 2005, p.39). Essa potência de afetação que as experiências estéticas propiciam, dos sentidos ao intelecto, são a base pela qual Read defende seu projeto educativo e formador, assim como, também, Jacques Rancière, propõe, pela educação estética, uma possibilidade de formação de comunidades expressivamente e diversamente livres.

Em ampla envergadura, devemos observar que a questão do desenho como membrana, se coloca como uma questão amplamente propositiva, produtora de sentidos e saberes, e, também, uma questão coletiva, pois a partilha do desenho como linguagem sensibilizadora nas escolas, nos cursos livres de artes ou na prática solitária, expressa e evidencia uma condição de liberdade imaginária e porosa, de instrumentalização dessa imaginação. Essa liberdade imaginária é fruto das condições de vida e do desenvolvimento de todo ser humano, garantidas pelo o estado, e, remanejadas a partir dos ritos institucionais e coletivos do poder - ritos estes, que são formas de partilha da cultura. Partilha física, formal, abstrata, efêmera. No avesso invisível desses questionamentos todos, o problema de se discutir o desenho em amplitude social, é o de se constatar a fragilidade em tentar confirmar sua prática como uma prova e uma evidência inquestionável de nossas misérias e lacunas, de nossos sintomas imaginários captados na forma de um exame gráfico; ou, de se constatar, também, o quanto o desenho se torna mais uma 


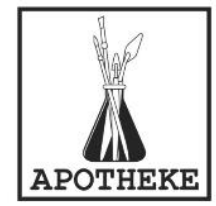

\section{REVISTA APOTHEKE}

ISSN 2447-1267

v.5, n.2, ano 5, 2019

ferramenta mnemônica oscilatória, e nem por isso menos precisa, dessa condição turbulenta que nos rodeia.

Ao pensar o desenho como uma ferramenta política e social em sua natureza de partilha, também passamos a entendê-lo e a exercê-lo como uma forma de manutenção da cultura e também da imaginação. Um procedimento criador de poros no sistema imaginário social, possibilitador de infiltrações, erosões, deslocamentos, contaminações e transbordamentos. compartilhamento de ideias, de posicionamentos críticos sobre determinados temas e a circulação das imagens enquanto discursos virulentos na era das redes sociais, recolocam o desenho no terreno das múltiplas possibilidades de projeção e reordenação desse mundo contemporâneo caótico.

Se a cultura nos separa da barbárie enquanto comunidades civilizadas, são justamente as ferramentas da cultura que dão corpo à possibilidade política de expressão, e vice-versa. Essa reciprocidade aponta novamente para uma capacidade de transformação social operada pelas práticas artísticas, e com o desenho não é diferente. Como nos fala Flávio Motta em seu texto, 'Desenho e emancipação' :

$\mathrm{Na}$ medida em que uma sociedade realiza suas condições humanísticas de viver, então o desenho se manifesta mais preciso e dinâmico em seu significado. Vale dizer que através do desenho podemos identificar o projeto social. E com ele encontraremos a linguagem adequada para conduzir a emancipação humana. (MOTTA, 1975, s/p).

Há de se pensar que essa linguagem adequada, seja ela qual for, é, sobretudo, aquela que nos desperta novas formas de sentir e agir, que abre possibilidades de construir e atuar socialmente no coro político de toda comunidade. A questão do desenho como um projeto de emancipação imaginária, está na sua atuação e transformação social a partir da sensibilização de outros olhares e outros imaginários, da afetação coletiva na produção do questionamento público que o dar-a-ver do seu exercício mostra além das linhas, traços e pontos; além do corpo do desenhador, de seus gestos e movimentos; de dentro de seu imaginário que 


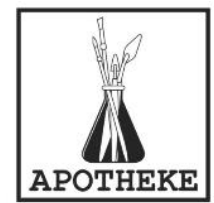

\section{REVISTA APOTHEKE}

ISSN 2447-1267

v.5, n.2, ano 5, 2019

transborda no agora da imagem grafada e reabitada por outras imaginações.

Essa porosidade que os pensamentos e ideias desenhadas despertam, fomentam outros pensamentos e novas imagens surgem em proliferação. Os processos de aprendizagem do desenho, que se mostram no próprio silêncio de sua imagem, ecoam como um projeto educador de sensibilidades e formador de olhares mais críticos, de olhares participativos dos processos formadores da cultura, da natureza, das instituições. A palavra 'desenho' neste momento, já perdeu a muito tempo sua significação de "coisa de lápis e papel", e se tornou uma operação multifacetada do imaginário no real, uma operação material e conceitual, uma operação da memória de um rastro ou mesmo a marca de uma fratura que se partilha sensível e socialmente, como significante e significado.

Observar para absorver, vazar e ser vazado, perceber para apreender, significar para compreender. Todos esses processos apontam para as camadas de operações e significados que o desenho transporta do pensamento para as superfícies do mundo e das superfícies do mundo para o pensamento. Nossos olhos recebem a luz do ambiente e movimentam-se em sua conjuntura anatômica pela força do desejo que move cada fibra e víscera, no exercício vital de ver e para ver. Perceptivelmente nosso sistema nervoso e muscular se integram para reagir as capturas do olho, reorganizadas pelo cérebro em imagens. Há um processo de integração com o mundo ao redor, que traça nossas ações na realidade, e esse processo tão básico, está na raiz do desenho como um processo de aprendizagem cultural. Para o filósofo alemão, Christoph Wulf:

Em ampla medida, a aprendizagem cultural é aprendizagem mimética, essencial em inúmeros processos de formação e de autoformação. Ela se estende ao outro, à comunidade social e aos bens culturais, cuja vitalidade é garantida por tal aprendizagem. A aprendizagem mimética, fundamentada no corpo e nos sentidos, permite a aprendizagem das imagens, dos esquemas, dos movimentos que dizem respeito à ação prática. Ela ocorre de maneira 


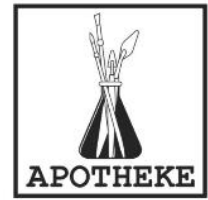

\section{REVISTA APOTHEKE}

ISSN 2447-1267

v.5, n.2, ano 5, 2019

amplamente inconsciente, o que induz efeitos duradouros em todos os campos da evolução cultural. (WULF, 2016, p. 557).

Se a aprendizagem mimética, que é praticada desde nossa primeira infância como forma de adquirir a linguagem gestual e oral, os códigos de comportamento e relação com o mundo, então, essa mesma aprendizagem, como já anunciada antes, é continuamente retrabalhada na educação estética. Tal aprendizagem, essencial ao nosso desenvolvimento cognoscível, é, também, a aprendizagem que toda prática de uma linguagem artística propicia ao corpo, ao pensamento, ao sujeito que a prática, refinando nesta prática, tanto os códigos dessa linguagem e sua capacidade comunicativa, quanto as percepções e reflexões adquiridas neste processo, gerando novos órgãos sensíveis, novas membranas imaginárias sobre uma determinada experiência de mundo, abrindo novas habilidades ao pensamento integrado ao corpo - e esse corpo integrado ao coro político do qual faz parte.

A questão política do desenho é que ele propicia, enquanto uma linguagem porosa, essa aprendizagem cultural integrada, que, por si só, gera um processo de educação estética emancipador do sujeito e o incentiva a produzir conteúdos novos de mundo-corpopensamento. Uma emancipação que fomenta todo sujeito a exercitar seu imaginário e a se encontrar com ele na primeira instância da produção artística, como testemunha, e, posteriormente, como público, na ação de partilha coletiva. Essa partilha se torna uma ação política de disseminação de imagens estranhas à um imaginário dominado e colonizado por imagens de um poder estagnado e em ruínas. A emancipação verdadeira é a possibilidade da mudança e da transformação dos contextos que nos cercam.

Como Flávio Motta recoloca precisamente: "O problema do desenho tem muito a ver com a nossa emancipação política" (MOTTA, 1975, s/p). Essa reflexão se torna o ponto de partida que gera - presente texto, pois ela reacende a possibilidade 


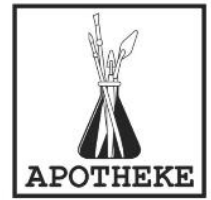

\section{REVISTA APOTHEKE}

ISSN 2447-1267

v.5, n.2, ano 5, 2019

instrumental, técnica e epistemológica do desenho operar transformações na maneira como imaginamos o mundo e interagimos com ele, não sendo uma fórmula mágica ou científica, apenas, mas, talvez, um pouco das duas, possibilitando experiências de disjunção à outros olhares, traçando encontros inesperados com pontos de vistas não vislumbrados e provocando o acréscimo de dobras e desdobramentos de um pensamento visual em outras imaginações criadoras e tantas outras emancipações. Segundo Rancière:

A política e a arte, tanto quanto os saberes, constroem ficções, isto é, rearranjos materiais dos signos e das imagens, das relações entre o que se vê e o que se diz, entre o que se faz e o que se pode fazer. (RANCIÈRE, 2005, p. 59).

Não seria o desenho uma prática que, em sua raiz, promove esses rearranjos materiais dos signos e das imagens? O mesmo rearranjo entre os corpos políticos e a partilha das imagens desenhadas, com novos distanciamentos e ressignificações das formas e de seus ritmos. O deslocamento que o desenho provoca é, ao mesmo tempo, a possibilidade do distanciamento crítico do referente e de nós mesmos como referentes - um deslocamento do pensamento a partir da imagem movendo a força da imaginação, e vice-versa. Essa força imaginária que é movida pelo desenho, também move os gestos e ações que podem redesenhar a política sobre os corpos, os comportamentos e as emancipações do pensamento através da imaginação. De certa maneira, pelo desenho ainda é possível se experimentar a construção de utopias, assim como, experimentar a projeção de mundos possíveis, do desenho e do por vir.

Dentro dos processos de aprendizagem, o ensino do desenho está inserido desde as formações básicas do humano até à universidade, o que revela como essa prática acompanha todas as nossas etapas do desenvolvimento imaginário, chegando a fazer parte, enquanto um saber, da cátedra universitária. Saber este, advindo das academias de desenho, que no Renascimento, a partir de seus ideais humanistas, se apropriam do desenho como uma 
ferramenta de conquista do real através das utopias da imaginação e das ficcionalizações desse real em imagens - imagens estas, que serviram de alimento para os movimentos emancipatórios do espírito humano desde aquela época. Vilanova Artigas, importante arquiteto modernista brasileiro, assim escreve sobre o desenho em um de seus textos célebres, pronunciado na aula inaugural da FAU-USP, em 1967:

No Renascimento o desenho ganhava cidadania. E se de um
lado é risco, traçado, mediação para expressão de um plano
a realizar, linguagem de uma técnica construtiva, de outro
lado é desígnio, intenção, propósito, projeto humano no
sentido de proposta do espírito. Um espírito que cria
objetos novos e os introduz no real. (ARTIGAs, 1967, s/p).

Neste apontamento histórico, do desenho como desígnio e como técnica, percebemos a dualidade tensionada entre o fazer e - pensar que essa linguagem nos pede. Dos processos de aprendizagem cultural aos processos de formação baseados nos princípios de uma educação estética, ou de uma educação pela arte, como queria Herbert Read, o projeto (trans)formador de toda prática artística torna-se um projeto social que desenha o futuro de uma comunidade, ou de um coletivo, enquanto uma existência possível para a liberdade expressiva - e para a expressividade política.

Como Christoph Wulf afirma sobre a aprendizagem estética: "A transmissão da cultura se dá nesses processos de encarnação e descoberta das produções culturais" (WULF, 2016, p.556). Essa transmissão, que assegura a sobrevivência de toda cultura é também um procedimento poroso de aprendizado, um processo delicado e sutil de construção de sentidos, onde os saberes, as formas de sentir e agir são transpostas a novos olhares, participando da formação dos imaginários e identidades culturais. Nesse sentido, retomar o desenho como uma questão social, sendo ele uma das linguagens mais antigas e presentes na história humana, retoma a urgência de reacender o seu sentido emancipatório de imaginários no agora, reassumindo e restaurando 


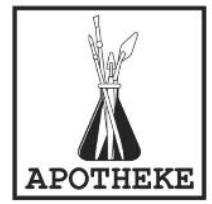

seu poder de construir ações de transformação no presente coletivo, real e ficcionalizado.

A proposição do desenho como membrana, em sua acepção semântica, de origem biológica e metafórica, enquanto, também, uma operação estética, talvez incida sobre uma questão ainda maior e impossível de ser respondida, que seria: qual a capacidade que nossos imaginários ainda possuem de se unirem em um único tecido, uma única pele, uma trama social contínua, sem topografias hierarquizadas de poder e opressão? Essa capacidade de união imaginária coincide com o desejo de juntar o que foi partilhado sensivelmente, refletindo, a partir do aprendizado estético, uma integração real, já apontada por Read em sua reforma pedagógica, onde a arte assumiria o papel integrador das sensibilidades psicofísicas e racionais, para a formação de sujeitos plenos e eficazes em suas formas de expressão, contribuindo com uma sociedade diversificada e igualitária.

Se com a arquitetura, o design e as artes gráficas, podemos ver uma sociabilização da arte do desenho, aplicada funcionalmente no espaço concreto e efetivo da vida cotidiana pela indústria, imaginemos então as transformações que o desenho pode operar na vida coletiva enquanto uma livre expressão do desejo, do pensamento e da possibilidade de comunicação com o outro. A capacidade de absorção do desenho por outro olhar, além daquele do desenhador do desenho, coloca o desenho no lugar de uma abertura do imaginário para outro imaginário, um lugar da partilha mesma das imagens e de um pensamento inquieto e inscrito na possibilidade da visão. Essa manobra de partilha e contaminação do imaginário, que existe na origem do desenho desde os tempos paleolíticos, coletiviza as mitologias, incendeia as rebeliões do espírito, adentra a ciência como uma possível visualização da verdade dos fenômenos, e hoje, no agora cibernético, fervilha na mão de qualquer pessoa curiosa o bastante para iniciar um risco, um traço, ao dar formas a uma linha, e, da linha, a um mundo. 


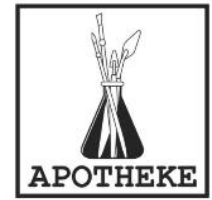

REVISTA APOTHEKE

ISSN 2447-1267

v.5, n.2, ano 5, 2019

Ao se traçar uma imagem, percebendo ou não, estamos destacando uma nova camada visível do mundo e do imaginário, trazendo aos olhos alheios o vislumbre dessa marca, dessa cicatriz provocada por uma abertura em nossa visão, uma cisão na forma de ver que tenciona o olhar a imaginar novas possibilidades para o real. O desenho, como ferramenta de conhecimento sensível, é, sobretudo, uma ferramenta de transformação social, pois emancipa a imaginação de forma porosa e educa sensivelmente as subjetividades políticas por evocar seus sentidos na ausência e na presença do olhar de um outro. Portanto, educar sensivelmente um sujeito é torná-lo capaz de desenhar seu projeto de vida, e assim, tornar a questão do desenho, a questão do desenhar ou do não-desenhar, uma questão que expressa a liberdade imaginária de um povo, a existência de uma comunidade, a pluralidade de um sujeito político que comunica, mesmo na ausência de palavras, a presença de seu posicionamento pela imagem.

Por fim, ou mesmo até os seus limites, o desenho, em seu sentido duplo e membranoso, será um ato de (re)existência e o gesto de uma imaginação política incendiária de outros imaginários. Em ambas as acepções, é o sistema poroso de suas operações, entre o nosso imaginário e o de outrem, que sutura a linha de uma fissura imaginária sempre a ser partilhada.

Desenhar, por si só, é perguntar-se do porquê do desenho, é questionar toda a falta e toda a necessidade que nos move a imaginar e a grafar, a grafar para imaginar, e, desse modo, permear outras camadas do visível, outros olhares, outras imaginações e outras camadas de nós mesmos; de permear o próprio desenho como membrana.

\section{BIBLIOGRAFIA}

ARTIGAS, Vilanova. "o desenho", Texto da Aula Inaugural pronunciada na Faculdade de Arquitetura e Urbanismo da USP em 1 de março de 1967. Reedição 
da publicação do Centro de Estudos Brasileiros do Grêmio da FAU-USP, 1975. Compartilhado por Rosa Artigas. Disponível em: https://www.archdaily.com.br/br/790124/o-desenho-vilanova-artigas

DERDYK, Edith. Disegno, desenho, desígnio. São Paulo: SENAC, 2007.

FERREIRA, Glória. Escritos de Artistas 60/70. Rio de Janeiro: Zahar, 2006.

FREUD, Sigmund. Pulsões e destinos da pulsão. In L. A. Hanns (Ed. e Trad.) Obras Psicológicas de Sigmund Freud: escritos sobre a psicologia do inconsciente. Rio de Janeiro: Imago, 1999.

MERLEAU-PONTY, Maurice. o olho e o espírito. São Paulo: Cosac Naify, 2013. MOTTA, Flavio Lichtenfels. Desenho e emancipação. Rio de Janeiro, 12 jul. 2019. Disponível em: http://winstonsmith.free.fr/textos/desenhoE-FLM.html. Acesso em: 15 ago. 2019 .

RANCIÈRE, Jacques. A partilha do sensível: estética e política. São Paulo: Editora 34, 2005 .

READ, Herbert. A educação pela arte. São Paulo: Martins Fontes, 2013. WULF, Christoph. Aprendizagem cultural e mimese: jogos, rituais e gestos. Rev. Bras. Educ., Rio de Janeiro, v. 21, n. 66, p. 553568, set. 2016 . Disponível http: //www.scielo.br/scielo.php?script=sci_arttext\&pid=S1413$24782016000300553 \& l n g=e n \& n r m=i s o$. Acesso em 15 jul. 2019.

\section{Márcio Diegues}

Endereço eletrônico do lattes:http://lattes.cnpq.br/3460122603859256

É artista e professor, pesquisa o desenho como fio condutor de suas relações com a paisagem e o espaço, desdobrando-o em gravuras, livros de artista, objetos, instalações, ações de coleta e obras site specific. É graduado em Artes Visuais pela UEL, Londrina, em 2012, e mestre em Linguagens Visuais pela EBA-UFRJ, em 2017. Atualmente reside no Rio de Janeiro, é doutorando no PPGARTS-UERJ e professor assistente de desenho, gravura e pintura na mesma instituição.

ORCID:

Recebido em 15 de julho de 2019. Aceito em 05 de agosto de 2019. 